\title{
A EQUAÇÃO FUNDAMENTAL DA CIÊNCIA DA INFORMAÇÃOO DE BROOKES E SUA IMPORTÂNCIA PARA O CAMPO DA CIÊNCIA DA INFORMAÇÃO
}

\author{
LA ECUACIÓN BÁSICA DE LA CIENCIA DE LA INFORMACIÓN DE \\ BROOKES Y SU IMPORTANCIA PARA EL CAMPO DE LA CIENCIA DE \\ LA INFORMACIÓN
}

Frederico Cesar Mafra Pereira - fmafra@eci.ufmg.br Doutorando em Ciência da Informação pela Escola de Ciência da Informação da Universidade Federal de Minas Gerais (ECI/UFMG). Consultor Empresarial.

\section{Resumo}

A partir da 'Equação Fundamental da Ciência da Informação', elaborada por Brookes, no início dos anos 80 , este artigo propõe uma rediscussão e um re-pensar acerca da relação entre informação e conhecimento. Apesar de passados mais de 25 anos, o trabalho de Brookes ainda hoje serve de referência para muitos autores que estudam a chamada "Sociedade da Informação" e a relação entre conhecimento e informação.

\author{
Palavras-chave \\ Ciência da Informação; Informação; \\ Conhecimento; Equação Fundamental da \\ Ciência da Informação; Paradigma cognitivo.
}




\section{INTRODUÇÃO}

A informação e o conhecimento como conceitos presentes na área da Ciência da Informação possuem várias definições, de acordo com diversos autores e suas linhas de atuação ou formação acadêmica / científica1. E muitos destes autores trabalham com conceitos que têm origem, ou fundamentação, na Equação Fundamental da Ciência da Informação, elaborada por Bertram C. Brookes, no início dos anos 80, cuja linha de estudo considera a Ciência da Informação a partir de uma visão cognitiva. Apesar de passados mais de 25 anos, sua contribuição para o campo da Ciência da Informação é inquestionável, e muitas atualizações foram e são feitas a partir desta equação, além dela servir como referência a diversos estudos, artigos, dissertações e teses da área.

O presente artigo busca, portanto, retomar a discussão sobre a 'Equação Fundamental da Ciência da Informação', fazendo uma re-leitura sobre o trabalho desenvolvido por Brookes, com foco prioritário na série de artigos referentes à Ciência da Informação, publicados por ele entre 1980 e 1981, intitulados 'The

\footnotetext{
1 Segundo Gonzales de Gomez (1990) e outros autores citados em Capurro e Hjorland (2003, p.356) - como Bodgan (BODGAN, R, J. Grounds for cognition. How goal-guided behavior shapes the mind. Hillsdale, NJ: Lawrence Earlbaum, 1994), a Ciência da Informação é "interdisciplinar" e/ou "transdisciplinar", e por isso, é questionável a possibilidade de se ter um significado comum para o conceito de informação.
}

Foundations of Information Science'. O objetivo será o de, num primeiro momento, identificar o contexto da época em que os artigos foram escritos, passando pela apresentação e explicação sobre a formulação da 'Equação Fundamental', e terminando com a apresentação das razões que explicam a motivação de Brookes em elaborar a referida equação. Num segundo momento, 0 artigo demonstrará a relevância do trabalho de Brookes para a área da Ciência da Informação. Para isso, será apresentado um levantamento, através de pesquisa bibliográfica, ou documental, sobre o número de referências ao trabalho de Brookes, utilizado pelos autores e cientistas da área da Ciência da Informação, tendo como fontes de referência a base de dados do Portal Capes - ISI Web of Science e as referências bibliográficas utilizadas nos artigos e trabalhos apresentados no $\mathrm{V}$ ENANCIB - Encontro Nacional de Pesquisa em Ciência da Informação, realizado em Belo Horizonte, em 2003, e no VI ENANCIB, realizado em Florianópolis, em 2005. Também, este trabalho discorrerá sobre autores que, a partir do trabalho de Brookes, desenvolveram adaptações e incrementações às definições sobre informação e conhecimento. Neste ponto, será comentado um estudo sobre a 'Equação do Impacto Informacional - Ell', 
de Araújo (2003), que tem como base a 'Equação Fundamental da Ciência da Informação' de Brookes.

\section{O CONTEXTO "PRÉ-EQUAÇÃO FUNDAMENTAL DE BROOKES"}

\subsection{A ciência da informação - teoria e campo de atuação}

Brookes (1980), quando da época da publicação de seus artigos 'The Foundations of Information Science', começa discorrendo sobre a Ciência da Informação e seu estado teórico, fazendo uma comparação desta com o surgimento de uma ciência em geral. Os problemas básicos da Ciência da Informação já eram considerados antigos por Brookes (1980), problemas estes epistemológicos, desde a teoria de Platão e a formalização da lógica de Aristóteles, bem como problemas relacionados à teoria do conhecimento, tanto na filosofia clássica, quanto na psicologia ou neurobiologia, ciências estas consideradas modernas e importantes. Segundo Brookes, para reivindicar o nome de Ciência da Informação, o teórico e sua respectiva teoria teriam que mostrar, de alguma maneira, que esta 'nova ciência' partia do que tratava a filosofia, a psicologia e a neurobiologia, apresentando novas áreas e problemas que poderiam ser, legitimamente, próprios desta nova ciência.
Brookes (1980) afirmou que o conceito de informação oferecia dificuldades peculiares ao cientista teórico. Mesmo no nível do senso comum, poderse-ia pensar que a informação é uma entidade que se difunde por toda a atividade humana. É difícil observar fenômenos da informação de forma isolada, com o destacamento que o método científico tradicional exige. $O$ próprio processo de descrever a observação de algum fenômeno é uma atividade própria da informação. Desta forma, é difícil manter separados os efeitos objetivos dos subjetivos, “...mas é possível uniformizá-los?", perguntou Brookes. Segundo o próprio, esta pergunta era crucial. Ele citou que, nas ciências naturais, supõe-se, com alguma confiança, que o observador não perturba os fenômenos que está observando, exceto, naturalmente, no nível da física quântica. Mas nas ciências sociais não se pode supor que o comportamento humano não é afetado pela observação ou pelas respostas inconscientes do observador ao comportamento daquelas pessoas que observa. O limite entre a descrição objetiva e a subjetiva torna-se, neste caso, muito confuso. Para Brookes (1980), todas as ciências sociais enfrentam esta dificuldade, mas nenhuma delas encarou-a de frente. $\mathrm{E}$, de todas as ciências sociais, a Ciência de Informação é a mais preocupada com as interações entre os processos mentais e 
físicos, ou entre as modalidades subjetivas e objetivas do pensamento humano. Ele afirmou que uma responsabilidade especial descansava, conseqüentemente, na Ciência da Informação, na busca de um esclarecimento sobre estas questões.

\subsection{Os paradigmas físico, cognitivo e social}

Brookes foi considerado um pioneiro na área da Ciência da Informação, se destacando e influenciando vários autores quanto ao estudo da Ciência da Informação a partir de uma visão cognitiva. Para entendermos, mais especificamente, essa linha de estudo de Brookes, abrir-se-á um espaço para discorrer sobre os paradigmas epistemológicos do século $X X$ - físico, cognitivo e social. Segundo Capurro (2003), a Ciência da Informação nasceu em meados do século $X X$, como teoria da 'recuperação da informação', baseada numa epistemologia fisicista. A esse paradigma, intimamente relacionado com a assim chamada 'Teoria da Informação' de Shannon e Weaver (19491972), e com a cibernética de Wiener (1961), deu-se o nome de 'paradigma físico' (ELLIS, 1992; OROM, 2000)². Esse

2 ELLIS, D. Paradigms and proto-paradigms in information retrieval research. In: PERTTI VAKKARI, Balise Cronin (Eds.). Conceptions of Library and Information Science: historical, empirical and theoretical perspectives. London, p.165-186, 1992, e OROM, Anders. Information Science, historical changes and social aspects: a nordic outolook. In: Journal of Documentation, v.56, n.1, p.12-26, 2000, apud Capurro (2003). paradigma postula que há algo, um objeto físico, que um emissor transmite a um receptor. Este objeto é denominado de 'mensagem', ou mais precisamente, 'signos', e não é chamado de informação. Informação seria o número de seleções ('choices') que implica a codificação da mensagem no momento de sua transmissão ${ }^{3}$. Capurro (2003) comenta que este paradigma físico exclui o papel ativo do sujeito cognoscente no processo de recuperação da informação científica, bem como em todo processo informativo e comunicativo. Portanto, essa teoria referese a um receptor da mensagem, e, por isso, seus limites conduziram ao paradigma oposto, o cognitivo.

\section{O paradigma cognitivo trata da} recuperação da informação, ou do conteúdo dos suportes físicos do conhecimento, sendo influenciado diretamente pela ontologia e epistemologia de Karl Popper (1972). Brookes, segundo Capurro (2003), subjetiva o modelo de Popper, no qual os conteúdos intelectuais formam uma espécie de rede que existe somente em espaços cognitivos ou mentais, e chama tais conteúdos de

\footnotetext{
3 Segundo Capurro (2003), os experimentos realizados pelo Cranfield Institute of Technology em 1957, para medir os resultados de um sistema computadorizado de recuperação da informação, marcam o começo da influência desse paradigma no campo da Ciência da Informação. Capurro completa dizendo que este "começo" foi problemático para a área.
} 
"informação objetiva"4. Sob a idéia deste paradigma é que Brookes desenvolve seu trabalho 'The foundations of Information Science' e a 'Equação Fundamental da Ciência da Informação'.

O paradigma social aparece como uma crítica ao paradigma cognitivo, considerado reducionista por Frohmann (1992), por considerar a informação, ou como algo separado do usuário localizado em um mundo numênico, ou de ver o usuário, se não exclusivamente como sujeito cognoscente, em primeiro lugar como tal, deixando de lado os condicionamentos sociais e materiais do existir humano. Considera o paradigma cognitivo não só como idealista, mas também como associal, e critica a

\footnotetext{
${ }^{4}$ Para Capurro e Hjorland (2003, p.392), a mais recente e fiel descrição da concepção cognitiva é apresentada por BORLUND, P. Evaluation of interactive information retrieval systems. Abo, Finland: Abo Academy University Press, 2000 -, sendo que eles vêem a concepção cognitiva assumindo uma posição entre o conceito objetivo da informação e a visão interpretativa e subjetiva e que é, de certa forma, comentado por Brookes em seu artigo The foundations of Information Science, part I, em 1980. Capurro (2003) também cita VAKKARI, Pertti. Task-Based Information Seeking. In: CRONIN, B. (Ed.). Annual Review of Information Science and Technology (ARIST), Medford, NJ. Information Today, v.37, p. 413-464, 2003, e INGWERSEN, P. Information Retrieval Interaction. London: Taylor Graham, 1992, INGWERSEN, P. Information and Information Science. In: Encyclopedia of Library and Information Science, v. 56, suppl.19, p. 137-174, 1995, e INGWERSEN, P. Cognitive Information Retrieval. In: WILLIAMS, Martha E. (Ed.). Annual Review of Information Science and Technology (ARIST), Medford, $\mathrm{NJ}$ : Information Today, v.34, 1999. Para ele, estes dois autores trabalham com idéias e conceitos que se encontram em uma posição intermediária entre 0 paradigma cognitivo mentalista de Brookes e o paradigma social.
}

epistemologia baseada em conceitos como 'imagens mentais', 'mapas cognitivos', 'modelos do mundo', 'realidades internas', etc.

\subsection{Os três mundos de Popper}

Brookes (1980) via a informação como um fenômeno relativamente específico para a Ciência da Informação, como um conhecimento comunicado e que opera uma transformação na estrutura de conceitos do indivíduo. Na sua tentativa de buscar uma definição de informação, Brookes (1980) toma a noção de conhecimento objetivo e cita Popper $(1972)^{5}$, afirmando que a Ciência da Informação necessita, em suas raízes, de um objetivo mais do que uma teoria subjetiva do conhecimento. Para Brookes (1980), toda linha de pensamento que reivindicar ser científica deve tratar com objetividades mais do que com subjetividades.

Apesar dos filósofos da época reconhecerem o mundo físico e o mundo mental como realidades independentes, Popper (1972) avançou nesta linha de pensamento, reconhecendo um terceiro mundo, o mundo do conhecimento objetivo, que é a totalidade do pensamento humano personificado em artefatos

\footnotetext{
5 Ver também POPPER, Karl R. Replies to my critics. In: SCHILPP, P.A. (Ed.). The Philosophy of Karl Popper. La Salle, IL: Open Court, p.949-1180, 1974, apud Capurro e Hjorland (2003).
} 
humanos, como nos originais, mas também na música, nas artes, nas tecnologias. Deste modo, Popper (1972) apresenta seu esquema ontológico dos 'três mundos': Mundo 1: O mundo físico, o mundo material (ou dos 'estados materiais'); Mundo 2: 0 mundo do conhecimento humano subjetivo ou dos 'estados mentais'; Mundo 3: $\mathrm{O}$ mundo do conhecimento objetivo, os produtos da mente humana como gravado nas línguas, nas artes, nas ciências, nas tecnologias em todos os artefatos humanos armazenados ou dispersados em torno da terra. "É o mundo das idéias no sentido objetivo, o mundo das teorias e das relações lógicas, dos argumentos e das situações problemáticas." (MARTELETO, 1987, p.172).

Para Popper (1972), estes três mundos são independentes, mas também interagem. Todos os seres humanos fazem parte do Mundo 1, o mundo físico, pois vivem na Terra, e dependem do oxigênio, do calor e da luz do sol, da água fresca, das substâncias materiais e proteínas, dentre outras, para existirem. Também fazem parte do Mundo 2, o mundo dos 'estados mentais', justamente por seu conhecimento subjetivo, presente nas mentes de cada indivíduo. E com relação ao Mundo 3, também fazem parte deste, pois seria o mundo do conhecimento objetivo, ou a totalidade de todo o pensamento humano implícito nos objetos elaborados pelo homem, como documentos, objetos artísticos ou tecnologias. Brookes (1980) cita que um artefato como representação do conhecimento (objetivo), permite que alguém saiba (ou obtenha conhecimento) sobre algo, mesmo que ele não interaja com o autor do artefato ${ }^{6}$. Ou seja, um ser humano talentoso pode adquirir um amplo conhecimento, a sabedoria profunda e ter insights espirituais, mas todo este conhecimento é perdido quando morre, à exceção daquele conhecimento que gravou em algum artefato. Para Brookes (1980), Popper (1972), no seu Mundo 3, reconheceu o valor inestimável do ser humano, principalmente quando do desenvolvimento da língua e da escrita, já que o Mundo 3, por ser essencialmente objetivo, é criado pelo homem, diferentemente da idéia de criação dos Mundos 1 e 2, que são atribuídos a um Deus ou a forças cósmicas.

Considerando essa posição, o Mundo 3 de Popper (1972) oferece uma racionalidade para as atividades desenvolvidas pelos profissionais da área

\footnotetext{
${ }^{6}$ Neste ponto, Brookes cita Popper (1972), quando este discorre sobre uma colméia de abelhas que, mesmo vazia, permite a quem a observa, um conhecimento sobre a colônia. Outro exemplo dado por Popper é com relação à possibilidade de ocorrência de uma catástrofe nuclear, que destruísse toda a "vida inteligente" na Terra, mas que não conseguisse destruir os artefatos produzidos. Neste caso, um outro ser que tivesse acesso a estes artefatos poderia obter conhecimento objetivo sobre a raça humana.
} 
da Ciência da Informação, já que podem expressar seu trabalho de forma prática e objetiva, através dos artefatos. Portanto, Brookes (1980) conclui que o mundo prático dos cientistas da área da Ciência da Informação pode ser o Mundo 3, utilizado para coletar e organizar os artefatos para o uso de outras pessoas. E o mundo teórico deve estudar as interações entre os Mundos 2 e 3, descrever e explicar se elas podem ajudar na organização do conhecimento mais do que os documentos em si. Ao adotar as interações entre os Mundos 2 e 3, o campo de estudo da Ciência da Informação estaria reivindicando um território que nenhuma outra disciplina já reivindicou. Ou seja, segundo Brookes (1980), é essa idéia de um estudo objetivo do conhecimento que justifica o estabelecimento de uma nova ciência. Neste ponto, afirma que esta nova ciência deveria ser uma mistura peculiar da lingüística, da comunicação, da informática, da estatística, dos métodos de pesquisa, juntamente com algumas técnicas da biblioteconomia, como a indexação e a classificação. Ou seja, toda a integração destes elementos deveria ser conseguida por quem a estuda e se interessa por ela. Ao mesmo tempo, Brookes (1980) alertou para a importância de que a Ciência da Informação seja uma disciplina que tenha seu próprio território original, seus próprios problemas originais e seu próprio ponto de vista original, relacionados aos casos humanos, e que desenvolva seus próprios princípios e técnicas.

\section{A "EQUAÇÃO FUNDAMENTAL DA CIÊNCIA DA INFORMAÇÃO" DE BROOKES}

\subsection{A relação entre informação e conhecimento: o estado "anômalo" do conhecimento}

Para Brookes (1980), a informação é um elemento que provoca transformações nas estruturas do indivíduo - estruturas que podem ser subjetivas ou objetivas, formadas por conceitos que estão ligados pelas relações que o indivíduo possui, ou a sua 'imagem do mundo', sendo a informação uma parte de tal estrutura. Esta informação (ou mensagem) é enviada através de um código conhecido, tanto pelo sujeito-emissor, quanto pelo sujeitoreceptor, podendo ser interpretada e, a partir daí, adquirir sentido. Ou seja, o sujeito social produz conhecimento quando recebe uma informação (com sentido) para resolver determinado problema ou se informar sobre qualquer situação, e se utiliza dela. Neste sentido, portanto, é que se apresenta uma relação entre informação e conhecimento, onde estes elementos podem provocar transformações nas estruturas de conceitos que o indivíduo possui.

Segundo Belkin (1980), cada indivíduo possui um estado (ou estados) de 
conhecimento sobre um determinado assunto e em um determinado momento, sendo este estado de conhecimento representado por uma estrutura de conceitos ligados por suas relações, ou pela 'imagem que ele tem do mundo'. No momento em que o indivíduo constata uma deficiência (ou anomalia) desse(s) estado(s) de conhecimento(s), ele se encontra em um 'estado anômalo de conhecimento'. Portanto, ao tentar obter uma informação ou um conjunto de informações que possam corrigir essa deficiência, o indivíduo cria um novo estado de conhecimento, que será aplicado na situação-problema, provocando uma nova situação ou uma transformação de estruturas.

\section{2 "A Equação Fundamental”}

Partindo do conceito de 'estado anômalo do conhecimento' e da relação entre informação e conhecimento na solução de uma situação 'anômala', Brookes (1980) expressou esse relacionamento entre a informação e o conhecimento através de uma fórmula, denominada por ele de 'A Equação Fundamental da Ciência da Informação':

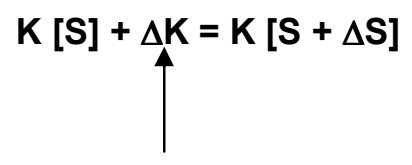

$\Delta \mathbf{l}$

Esta equação exprime a passagem de um estado de conhecimento ('anômalo')
$\mathrm{K}[\mathrm{S}]$ para um novo estado de conhecimento $\mathrm{K}[\mathrm{S}+\Delta \mathrm{S}]$, devido à contribuição de um novo conhecimento $\Delta \mathrm{K}$, extraído de uma informação $\Delta \mathrm{l}$; sendo que o termo $\Delta S$ indica $\mathrm{o}$ efeito dessa modificação. Dessa forma, ocorre a transformação do estado inicial de conhecimento, sendo que, se tal transformação for aplicada ao nível das relações que ocorrem num determinado contexto social, pode-se ter a transformação deste contexto. Este processo tem características transformadoras, pois possibilita uma revisão do conhecimento estabelecido e/ou a criação de novos conhecimentos. A idéia básica é a de que o conhecimento se dá quando a informação é percebida e aceita, sendo toda alteração provocada no estoque mental de saber do indivíduo, oriunda da interação com estruturas de informação.

A partir das considerações feitas, compreendemos que a informação é uma prática social que envolve ações de atribuição, e comunicação de sentido que, por sua vez, podem provocar transformações nas estruturas, pois geram novos estados de conhecimento (ARAÚJO, 2003, p.4).

Brookes (1980) expressou a equação numa forma 'pseudo-matemática', porque foi a maneira que encontrou de mostrar a relação entre a informação e o conhecimento da maneira mais compacta possível. Mas afirmou também que um 
matemático notará que os termos e símbolos utilizados são indefinidos. $\mathrm{Na}$ realidade, a equação diz pouco a mais do que Brookes vinha discorrendo sobre o tema, e que serviu para enfatizar como ele pouco sabia, na época, sobre as maneiras em que o nosso conhecimento (das pessoas) cresce e se desenvolve. Há, entretanto, um ponto implícito na equação, mas que foi comentado por Brookes (1980) e destacado por Marteleto (1987, p.172):

Essa equação implica que essas entidades (informação e conhecimento) são mensuráveis, podendo ser medidas através das mesmas unidades, isto é, a informação e o conhecimento são fenômenos do mesmo tipo. Assim definida, a informação é um pequeno bit do conhecimento.

A equação mostra também, conforme Brookes (1980), que o crescimento do conhecimento não é simplesmente incremental. A absorção da informação em uma estrutura do conhecimento pode causar não simplesmente uma adição, mas algum ajuste à estrutura, uma mudança nas relações que ligam dois ou mais conceitos já admitidos. Brookes (1980) também afirma que, de acordo com a equação, a informação pode depender da observação sensorial, mas os dados recebidos teriam que ser subjetivamente interpretados por uma estrutura de conhecimento para se transformar em informação. Para ele, a equação fundamental se aplica às estruturas subjetivas e objetivas do conhecimento. Concorda com Popper (1972), quando este diz que os indivíduos aprendem mais sobre a aprendizagem subjetiva estudando a 'Equação Fundamental' num contexto objetivo do que nos contextos subjetivos tradicionais, e sugere que este tipo de estudo seja um alvo principal e importante da Ciência da Informação.

Tomando-se por base a 'Equação Fundamental', Brookes (1980) afirma que, se houver um conhecimento objetivo, então deve também existir uma informação objetiva correspondente. A idéia do 'perceptor', pronto para transmitir a informação ao sujeito-receptor, é ajustada para a coleta de pontos que permitam que a informação se torne objetiva. Ou seja, a informação objetiva é aquela que pode ser compartilhada por qualquer um (sujeitoemissor) que se identificou com outro (sujeito-receptor) de alguma forma. Mas quando essa informação objetiva alcança o sujeito-receptor, torna-se subjetiva para ele, e a cada um dos que também receberem esta informação. Um exemplo citado por Brookes (1980) seria o caso da informação transmitida através do rádio. Esta informação é objetiva porque é compartilhada e recebida por todos que estão escutando o rádio. Entretanto, o que os ouvintes ouvem como sendo informação objetiva pode ser a opinião subjetiva de algum comentarista político que traga à 
lembrança dos ouvintes suas próprias respostas subjetivas ao seu comentário. Mas se a informação, considerada uma seqüência programada de sinais, não for estruturada no conhecimento do indivíduo, permanece como informação objetiva.

Brookes (1980) relembra que as medidas da informação objetiva foram propostas há 50 anos (tomando-se como base a época em que escreveu seu artigo, em 1980), e são usadas na teoria de Shannon (1948) aplicada aos sistemas de telecomunicações e aos computadores. E tais medidas ainda não tinham sido aplicadas no estudo do conhecimento objetivo, mas que, ao mesmo tempo, não via nenhum empecilho para que fossem. $\mathrm{O}$ que Brookes (1980) afirmou é que o crescimento do conhecimento observável publicamente como aquele gravado na literatura e publicado reflete os caminhos em que as mentes individuais pensam confidencialmente. Em todo o caso, não há nenhuma maneira de inspecionar as estruturas confidenciais do conhecimento de um indivíduo sem eliciar sua resposta a perguntas, através de examinações escritas. Em estudos subjetivos, os cientistas têm que usar 'técnicas da caixa preta' para encontrar a estrutura confidencial do conhecimento, dando forma ao que quer que eles tentem obter de resposta, comparando a saída com as suas próprias estruturas subjetivas. Esta parece ser uma técnica metodologicamente precária para ser adotada, segundo Brookes (1980), já que o mesmo problema pode ser estudado objetivamente.

\section{A RELEVÂNCIA DA EQUAÇÃO FUNDAMENTAL DE BROOKES PARA $\mathrm{ACl}$}

Como forma de demonstrar a importância do trabalho de Brookes (em especial, sobre a equação fundamental da ciência da informação) para a área, é apresentada uma síntese do número de autores, do início da década de 80 até agosto de 2006, que se utilizaram (e/ou ainda se utilizam) dos artigos de Brookes 'The foundations of Information Science part I, II, III and IV' como referência em diversos tipos de trabalhos na área ${ }^{7}$.

${ }^{7}$ Pensou-se, também, na utilização de mais duas fontes de informação. A primeira seria a Biblioteca da Escola de Ciência da Informação da UFMG "Profa. Etelvina Lima" -, onde seria feito um levantamento, através do sistema de informações da biblioteca, do número de empréstimos do Journal of Information Science, no qual constam os artigos de Brookes 'The foundations of Information Science'. Os dados coletados não permitiriam uma conclusão precisa de que o número de empréstimos deste exemplar fosse idêntico ao número de consultas aos artigos de Brookes, mas poderíamos pressupor que, dada a importância de seus estudos, estes poderiam se constituir na razão principal, ou em uma das razões principais que justificariam a procura pelo exemplar do Journal of Information Science. Entretanto, tal levantamento não foi feito, dada a "impossibilidade" do sistema de informações da biblioteca de processá-lo a contento. Mas, a título de curiosidade, o referido exemplar do JIS com os artigos de Brookes foi solicitado 23 vezes junto à biblioteca, de junho de 1983 a agosto de 2006 - com base na ficha de marcação interna do exemplar -, o que pode demonstrar o constante interesse de estudiosos da área sobre o tema e o autor. Uma segunda fonte de 
A metodologia empregada para 0 levantamento destas informações foi a de pesquisa bibliográfica, ou documental. Este método de pesquisa é também chamado de "levantamento em fontes secundárias", e de acordo com Mattar (1996, p.20) e Mafra Pereira (2000, p.31),

[...] Uma das formas mais rápidas e econômicas de amadurecer ou aprofundar um problema de pesquisa é através do conhecimento dos trabalhos já feitos por outros, via levantamentos bibliográficos. Este levantamento deverá envolver procura em livros sobre 0 assunto, revistas especializadas ou não, dissertações e teses apresentadas em universidades e informações publicadas por jornais, órgãos governamentais, sindicatos, associações de classe, concessionárias de serviços públicos, etc. (MATTAR, 1996, p.20).

O levantamento de dados secundários compreende levantamentos bibliográficos, documentais, estatísticas e levantamento de pesquisas realizadas. Os dados secundários podem advir de fontes internas e/ou externas à instituição contratante da pesquisa e deve-se ater para a importância de se coletar dados

informações que poderia ser utilizada seria a das referências bibliográficas das disciplinas ministradas no Programa de Pós-Graduação da ECl-UFMG. A intenção inicial é que tivéssemos uma idéia do número de vezes que o trabalho de Brookes (1980) apareceria como referência principal das disciplinas, ou como referência secundária nos artigos e livros recomendados por cada professor. Entretanto, tal informação também não pôde ser trabalhada, pelo fato das disciplinas do Programa mudarem constantemente, bem como os professores que as ministram. Porém, essas duas fontes alternativas de informação poderiam ser utilizadas em trabalhos posteriores, ou num aprofundamento do tema deste trabalho. secundários através de fontes primárias (MAFRA PEREIRA, 2000, p.31).

De acordo com a base de dados do 'Portal Capes - ISI Web of Science', desde 1981, um ano após a publicação dos artigos de Brookes (1980), até agosto de 2006, foram identificados 108 trabalhos que apresentam, em suas referências bibliográficas, as quatro partes ou pelo menos uma das quatro partes do trabalho de Brookes 'The foundations of Information Science, ${ }^{8}$ :

- 88 trabalhos citaram a Parte I 'Philosophical Aspects';

- 29 trabalhos citaram a Parte II 'Quantitative aspects: classes of things and the challenge of human individuality';

- 30 trabalhos citaram a Parte III 'Quantitative aspects: objective maps and subjective landscapes';

- 31 trabalhos citaram a Parte IV 'Information science: the changing paradigm'.

São, ao todo, 106 autores diferentes, que apresentaram trabalhos individuais ou em parceria com outros autores, e que citam os artigos de Brookes como referência.

\footnotetext{
${ }^{8}$ Este trabalho focou apenas os quatro artigos do estudo 'The foundations of Information Science', de Brookes. Entretanto, se a pesquisa fosse estendida para os demais estudos e artigos de Brookes, os números de referências aumentariam consideravelmente.
} 
Outra fonte de pesquisa utilizada foi o conjunto de referências bibliográficas dos trabalhos e artigos apresentados no $\mathrm{V}$ ENANCIB - Encontro Nacional de Pesquisa em Ciência da Informação, realizado entre os dias 10 e 14 de novembro de 2003, na ECI/UFMG, Belo Horizonte (MG), e no VI ENANCIB, realizado entre os dias 28 e 30 de novembro de 2005, em Florianópolis (SC). Por se tratar de um dos eventos mais importantes da área da Ciência da Informação no Brasil, esta fonte de informação foi escolhida para mostrar, dentre os mais recentes trabalhos apresentados na área da Ciência da Informação no país, a contribuição dos estudos de Brookes (1980) como referência, principal ou secundária. Do total de 140 trabalhos apresentados no V ENANCIB, incluindo o texto da Conferência de Abertura, oito deles destacaram Brookes (1980) como referência bibliográfica ou como citação, por outros autores, no corpo dos artigos. Nestes oito trabalhos, Brookes foi citado 27 vezes. Com relação às citações, seis trabalhos citaram partes do artigo 'The Foundations of Information Science', e dois citaram outros artigos de Brookes. No VI ENANCIB o artigo de Brookes (1980) foi citado por apenas um trabalho, dentre os 125 apresentados.
Os estudos de Brookes (1980) sobre a equação fundamental da ciência da informação são importantes e ainda hoje são utilizados por diversos de seus pares, nas diversas linhas de pesquisa dentro da área da Ciência da Informação, ou como referência principal para o desenvolvimento de novas propostas, ou como base para uma contra-opinião (crítica) e a exposição de uma nova idéia na área. De qualquer forma, a utilização de seus trabalhos como referência é presente e inquestionável.

\section{ATUALIZAÇÕES DA “EQUAÇÃO FUNDAMENTAL"}

Dentre os diversos trabalhos que utilizam os estudos de Brookes (1980) na área da Ciência da Informação, este artigo destaca um em especial, apresentado no $\mathrm{V}$ ENANCIB (2003), de Eliany Alvarenga de Araújo, intitulado 'Equação do Impacto Informacional: uma proposta paradigmática'. Segundo a autora,

0 texto analisa aspectos conceituais da informação e propõe uma nova conceituação para a mesma. A partir da equação fundamental da Ciência da Informação elaborada por Brookes, analisa as possibilidades de se avaliar o impacto da informação nos contextos mental e/ou social. Apresenta uma proposta paradigmática para a avaliação do impacto da informação através da EQUAÇÃO DO IMPACTO INFORMACIONAL - EII (ARAÚJO, 2003, p.1).

Este estudo apresenta, na sua parte inicial, a compreensão sobre o termo 
informação segundo Brookes (1980), além do conceito de 'estado anômalo do conhecimento', e retoma a 'Equação Fundamental da Ciência da Informação' como ponto de partida para sua proposta. Araújo (2003) destaca a importância de se considerar o sujeito do conhecimento tanto o sujeito-usuário quanto o sujeitogerador -, como forma de se compreender melhor o fenômeno informacional, e apresenta três tendências, no campo da Ciência da Informação, sobre esse tema. A primeira fala sobre a informação como produção de um sujeito universal, considerando este sujeito portador de categorias e operações estabelecidas "a priori", sendo que este sujeito do conhecimento (usuário ou gerador de informação) desenvolve práticas informacionais. Para Araújo (2003), esta interpretação do fenômeno informacional é de difícil aceitação, já que considera o sujeito do conhecimento um ente abstrato, um ente a-histórico. A segunda abordagem fala sobre a informação como produção de um sujeito cognitivo-individual que, a partir de suas experiências individuais, combina percepções elementares e as generaliza, dando lugar a produtos mais complexos, como o conhecimento científico. Esta abordagem enfatiza a dimensão subjetiva do processo informacional, onde as práticas de informação (recepção, geração e transferência) são ações que ocorrem no "interior" de um sujeito cognitivo individual, e não são estabelecidas a priori. Entretanto, também segundo Araújo (2003), esta abordagem acaba por aprisionar o sujeito do conhecimento num universo de escolhas mecânicas. A autora destaca que as duas abordagens anteriores desconsideram um terceiro elemento importante no processo informacional, que é a realidade social. Neste sentido, apresenta uma terceira abordagem que considera a informação como produção de um sujeito cognitivosocial, sendo as práticas informacionais mediadas por um sistema de conceitos, que constituem um "modelo" de mundo para o sujeito do conhecimento, e que opera como uma unidade de seleção na "filtragem" e estruturação, tanto da emissão, como na recepção da informação. O elemento diferenciador desta abordagem para as duas anteriores é o ponto de vista que relaciona o sujeito do conhecimento com seu contexto social. Segundo Gonzalez de Gomez (1984, p.112),

Esse modelo conceitual depende das experiências anteriores de um indivíduo ou grupo, sendo afetado pelos processos de socialização que recebem os indivíduos e pela vivência histórica dos grupos sociais. São, como preferimos dizer, modelos sócio-cognitivos ${ }^{9}$.

\footnotetext{
9 Araújo (2003) cita também outros autores que desenvolveram seus estudos incorporando a dimensão sócio-cultural das práticas informacionais, como HJORLAND, B., ALBRECHSTSEN, H. Toward a new horizont information science: domain analyses. Journal of American Society of
} 
Araújo (2003) conclui que o fenômeno informacional não é "algo natural", pois se dá a partir de um sujeito cognitivo e também social, sendo a informação uma construção do sujeito cognitivo-social. Com isso, admite-se que 0 processo informacional é constantemente reconstruído pelo sujeito do conhecimento, a partir de uma determinada realidade social e de significativos pessoais, não sendo $\mathrm{o}$ ato de informar-se um processo finalizado quando $o$ sujeito do conhecimento recebe e usa a informação, mas sim algo aberto e inacabado, sempre propício a reestruturações e criação de novas informações. Neste ponto, Araújo (2003) aborda em seu trabalho o aspecto da função da informação na sociedade atual, e então, toma como ponto de partida a 'Equação Fundamental da Ciência da Informação' de Brookes (1980) para buscar ampliar a compreensão sobre a relação informação e sociedade, e sobre o novo estado do conhecimento - $\mathrm{K}[\mathrm{S}+\Delta \mathrm{S}]$ proveniente de uma determinada informação - $\Delta \mathrm{l}$. Apresenta, enfim, sua 'Equação do Impacto Informacional - Ell' 10. $\mathrm{IF}=\mathrm{Ni}+\mathrm{Cs} \times \operatorname{Int}$

Information Science, v.46, p. 400-425, 1995, e WERSIG, G. Information Science needs a Theory of a Information Actions. Social Science Information Studies, v.5, p.11-23, 1985.

${ }^{10}$ Esta equação surgiu de pesquisa desenvolvida pela autora em sua tese de doutorado, que analisava a relação entre as práticas informacionais e as práticas de cidadania no contexto de atuação de Organizações Não-Governamentais (ONGs) brasileiras. E destaca que outros estudos estão
Esta equação permite que se conheça o nível de transformação ocorrido nos sujeitos sociais e nas formações sociais correspondentes, pois a mesma reúne, num só momento, os elementos caracterizadores da transformação / mudança mental e/ou social.

[...] a profundidade do impacto da informação sobre os sujeitos sociais e suas respectivas práticas relaciona-se diretamente, por um lado, às necessidades informacionais (Ni) e aos contextos sociais vivenciados (Cs) por tais sujeitos e, por outro lado, à intencionalidade (Int) explícita ou não da informação disseminada e/ou utilizada (ARAÚJO, 2003, p.12) ${ }^{11}$.

Mesmo tendo avançado, em seu trabalho, para o conceito de informação como construção de um sujeito cognitivosocial, diferentemente de Brookes (1980), que trabalhou com a idéia do paradigma cognitivo, Araújo (2003) utilizou-se da referência de Brookes (1980) e a 'Equação Fundamental' para propor a sua 'Equação do Impacto Informacional' neste novo contexto. Portanto, a referência de Brookes

sendo desenvolvidos junto a alguns contextos sociais específicos, objetivando a verificação desta Equação do Impacto Informacional.

11 Araújo (2003) destaca que o elemento da intencionalidade, que surge como o elemento mais subjetivo da Equação do Impacto Informacional (EII), ainda não tem sido considerado, em termos teórico-conceituais, na área da Ciência da Informação. No caso da ElI, a intencionalidade é utilizada no sentido fenomenológico, como direção, orientação que dá sentido ao ato de entendimento. A autora destaca, portanto, que a análise da intencionalidade pode revelar a relação que se estabelece entre a consciência e o real e as transformações ou impactos da informação ocorridos em tal consciência. 
(1980) foi importante para fundamentar as idéias e novos conceitos apresentados por Araújo (2003), mesmo que a autora tenha avançado, ou desenvolvido seu estudo, sob um paradigma diferente ${ }^{12}$.

\section{CONSIDERAÇÕES FINAIS}

Conforme exposto na parte introdutória deste trabalho, o objetivo maior deste foi abordar a contribuição de Brookes (1980), e de sua 'Equação Fundamental da Ciência da Informação', para o campo da Ciência da Informação, e rediscutir e repensar o tema deve fazer parte do trabalho de estudiosos da área. Como visto durante todo $\mathrm{O}$ artigo, e no estudo apresentado por Araújo (2003), as idéias de Brookes (1980) apresentadas em 'Foundations of Information Science' ainda são uma forte referência no campo da Ciência da Informação e podem servir de modelo preliminar para o surgimento, incrementações ou ampliações de conceitos e idéias. Várias das definições modernas sobre informação e conhecimento, e sobre a relação entre eles, baseiam-se, sob o ponto de vista

${ }^{12}$ Como referência complementar, ver MENOU, M. J., The Impact of information I: Toward a research agenda for its definition and measurement. Information Processing and Management, v.31, n.4, p. 455-477, 1995, e MENOU, M. J., The Impact of information II: Concepts of information and its value. Information Processing and Management, v.31, n.4, p.479-490, 1995. Este autor atua como consultor internacional independente em Gestão do Conhecimento e da Informação, e tem estudos sobre o impacto e o valor da informação, utilizando como referência, também, a Equação Fundamental de Brookes (1980). epistemológico, nos conceitos que Brookes (1980) apresentou há 26 anos.

Nos dias atuais, sob o contexto do paradigma social, não deixamos de considerar importante a questão cognitiva do sujeito do conhecimento, e Brookes (1980) já afirmara e considerara, mesmo que conceitualmente presente em um paradigma cognitivo, que a transformação do estado inicial de conhecimento, demonstrada na 'Equação Fundamental', pode ocorrer no nível das relações que ocorrem num determinado contexto social, acarretando na transformação deste contexto. Estudos sobre este atual paradigma social e a atuação neste de um "sujeito cognitivo social", conforme mencionado por Araújo (2003), podem utilizar as idéias de Brookes (1980) como ponto de partida, um modelo a ser ampliado e incrementado.

\section{REFERÊNCIAS}

ARAÚJO, Eliany Alvarenga de. Equação do Impacto Informacional: uma proposta paradigmática. In: ENCONTRO NACIONAL DE PESQUISA EM CIÊNCIA DA INFORMAÇÃO - ENANCIB, 5., 2003, Belo Horizonte. Anais... Belo Horizonte: ECI/UFMG, 2003.

BELKIN, N.J. Anomalous states of knowledge as a basis for information retrieval. Canadian Journal of Information Science, n.5, p.133-143,1980.

BROOKES, B. C. The foundation of Information Science. Journal of Information Science, v. 2, Part I (p.125-133), Part II 
(p.209-221), Part III (p.269-275), and v. 3, Part IV (p.3-12), 1980/1981.

CAPURRO, R. Epistemologia e Ciência da Informação. In: ENCONTRO NACIONAL DE PESQUISA EM CIÊNCIA DA INFORMAÇÃO - ENANCIB, 5., 2003, Belo Horizonte. Anais... Belo Horizonte: ECI/UFMG, 2003.

CAPURRO, R.; HJORLAND, B. The Concept of Information. ARIST, v.37, p. 343-411, 2003.

FROHMANN, Bernd. The power of images: a discourse analysis of the cognitive viewpoint. Journal of Documentation, v.48, n.4, p.365-286, 1992.

GONZALEZ DE GOMEZ, Maria Nélida. Informação e conhecimento. Ciência da Informação, Brasília, v.13, n.2, p. 107-114, jul./dez., 1984.

GONZALEZ DE GOMEZ, Maria Nélida. O objeto de estudo da Ciência da Informação: paradoxos e desafios. Ciência da Informação, Brasília, v.19, n.2, p. 117-122, jul./dez., 1990.

MAFRA PEREIRA, Frederico C. Fundamentos metodológicos da pesquisa de marketing. 2000. 68 f. Monografia (Especialização lato sensu em Gestão Estratégica de Marketing) - Centro de PósGraduação e Pesquisas em Administração da Universidade Federal de Minas Gerais, Belo Horizonte, 2000.

MARTELETO, Maria Regina. Informação: elemento regulador dos sistemas, fator de mudança social ou fenômeno pósmoderno? Ciência da Informação, Brasília, v.16, n.2, p. 169-181, 1987.

MATTAR, Fauze Najib. Pesquisa de Marketing. São Paulo: Atlas, 1996.

POPPER, Karl R. Objective Knowledge: an evolutionary approach. Oxford : Clarendon Press, 1972.
SHANNON, C. A Mathematical theory of communication. Bell System Technical Journal, v.27, p.379-423, p.623-656, 1948.

SHANNON, Claude; WEAVER Warren. The mathematical theory of communication. Urbana, IL: University of Illinois Press, 1949/1972.

WIENER, Norbert. Cybernetics or the control and communication in the animal and the machine. Cambridge: MIT Press, 1961.

\section{Title}

The fundamental equation of Brookes' Information Science and its importance to the Information Science field.

\section{Abstract}

This article aims to arise some aspects that allow to re-discuss and to re-think the relation between information and knowledge, from the 'Fundamental Equation of the Information Science', elaborated by Brookes, in the beginning of the 80's. Although it has passed more than 25 years, it is still used as reference or preliminary model by many authors who study the called "Information Society" and the relation between knowledge and information.

\section{Keywords}

Information Science; Information; Knowledge; Fundamental Equation of Information Science; Cognitive Paradigm.

\section{Titulo}

La Ecuación Básica de la Ciencia de la Información de Brookes y su importancia para el campo de la ciencia de la información

\section{Resumen}

Este artículo pretende traer a la luz aspectos que permiten volver a discutir y pensar la 
relación entre la información y el conocimiento a partir de la "Ecuación Básica de la Ciencia de la Información", elaborada por Brookes en los principios de los 80 . Pasados más de 25 años, todavía sirve como referencia o modelo preliminar para muchos autores que estudian la llamada "Sociedad de la Información" y la relación entre el conocimiento y la información.

\section{Palabras clave}

Ciencia de la Información; Información; Conocimientos; Ecuación Básica de la Ciencia de la Información; Paradigma cognitivo.

Recebido em: 27/02/2008

Aceito em: 29/04/2008 